\section{Field and Laboratory Resistance of St. Augustinegrass Germplasm to the Southern Chinch Bug}

\author{
Philip Busey \\ Fort Lauderdale Research and Education Center, Institute of Food and \\ Agricultural Sciences, University of Florida, 3205 College Avenue, Fort \\ Lauderdale, FL 33314
}

Additional index words. breeding, cultivar, germplasm, insect, sod, turf, Stenotaphrum secundatum, Blissus insularis

\begin{abstract}
St. Augustinegrass [Stenotaphrum secundatum (Walt.) Kuntze] is host to the southern chinch bug (SCB) (Blissus insularis Barber). This study evaluated and compared field and laboratory resistance of St. Augustinegrass germplasm to the SCB. Turf field plots of $20 \mathrm{St}$. Augustinegrass genotypes were monitored monthly for 2 years for damage by the SCB. After each occurrence of damage, plots were treated individually with an insecticide and allowed to become damaged again. Genotypes differed in frequency of damage, which varied from 1.02 occurrences per year for FX-22 and FX-338 to zero occurrences per year for 'Floratam'. During the next 2 years when no insecticide was applied, the portion of dead canopy varied from $86 \%$ for FX-313 to $0 \%$ for 'Floratam'. In a second field experiment, SCB damage was evaluated in 10 polyploid St. Augustinegrass genotypes. Damage varied from $90 \%$ for 'Bitterblue' to $0 \%$ for 'FX-10'. Oviposition rate was determined from SCB confined in the laboratory on genotypes from both field experiments. Oviposition rate differed among genotypes and predicted $\left(P<0.01 ; r^{2}=0.67\right.$ to 0.79 ) field damage. To my knowledge, this paper is the first to report field resistance to the SCB in St. Augustinegrass, validating the use of laboratory bioassays.
\end{abstract}

St. Augustinegrass turf, the primary host of the southern chinch bug (SCB), is damaged when the SCB attains a population of 800 adults $/ \mathrm{m}^{2}$ (Busey and Snyder, 1993). The rapid outbreak and damage induced by the SCB makes it difficult to study in the field. Host resistance to the SCB was discovered in the laboratory by Reinert and Dudeck (1974) and contributed to the release of the cultivar Floratam St. Augustinegrass (Horn etal., 1973). The resistance of 'Floratam' to the SCB has been confirmed in numerous laboratory bioassays (reviewed by Quisenberry, 1990). Host suitability criteria include SCB oviposition rate and survival (Reinert and Dudeck, 1974), longevity (Busey and Center, 1987), and excreta production (Busey, 1990b; Busey and Zaenker, 1992). Field resistance of St. Augustinegrass to the SCB has been mentioned in anecdotes by turfgrass managers but never documented.

Received for publication 6 Mar. 1995. Accepted for publication 3 July 1995. Florida Agricultural Expt. Station Journal Series no. R-04397. This study was supported in part by the Florida Turfgrass Association in cooperation with the Turfgrass Producers Association of Florida. I am grateful for field support by A. Duda \& Sons, under the supervision of Dave B. Basquin, and technical assistance by Barbara J. Center, Warren S. Kolbert, Kristin E. Leo, and Rodrigo Moriones. The cost of publishing this paper was defrayed in part by the payment of page charges. Under postal regulations, this paper therefore must be hereby marked advertisement solely to indicate this fact.

HortScience, Vol. 30(6), OCtober 1995 with methyl bromide at $51 \mathrm{~g} \cdot \mathrm{m}^{-2}$. Plots were irrigated with $18 \mathrm{~mm}$ of water during the night following observation of wilt and were mowed about every 2 weeks at $65 \mathrm{~mm}$. Plots were fertilized with $16 \mathrm{~N}-2 \mathrm{P}-7 \mathrm{~K}$ at $19,22,10,10$, and $0 \mathrm{~g} \mathrm{~N} / \mathrm{m}^{2}$ per year in 1987, 1988, 1989, 1990, and 1991, respectively. Nitrogen source was primarily $\mathrm{NH}_{4} \mathrm{NO}_{3}$. Stolons encroaching in alleyways between plots were treated selectively with glyphosate. Fire ants (Solenopsis invicta Buren) were treated with $30 \mathrm{~g}$ hydramethylnon/mound. No broadcast pesticides were applied.

Beginning 13 May 1987, SCB damage was noticed in some plots, characterized by patches of chlorotic leaf blades ( $<5 \%$ canopy) associated with SCB. SCB were avirulent (did not survive on the resistant 'Floratam' in the laboratory); thus, they were designated as the standard population (STD) (Busey and Center, 1987) SCB. Plots were monitored monthly through 11 June 1989, treated individually with insecticide $[0.2 \mathrm{~g} O, O$-diethyl $O$ - $(3,5,6$ trichloro-2-pyridinyl) phosphorothioate (chlorpyrifos) $/ \mathrm{m}^{2}$ or $0.9 \mathrm{~g} O, O$-diethyl $O$-[6methyl-2-(1-methylethyl)-4-pyrimidinyl] phosphorothioate (diazinon) $/ \mathrm{m}^{2}$ following each occurrence of damage, and then allowed to become damaged again. Damage frequency per plot was calculated by dividing the number of occurrences of SCB damage by the observation period (2.08 years). Insecticides were discontinued in June 1989, and St. Augustinegrass plots were allowed to be progressively damaged by SCB. Extent of damage was estimated visually as a percentage of dead canopy from July through November in 1990 and 1991. For analysis, months were pooled as repeated measures.

To estimate St. Augustinegrass resistance in the laboratory, STD SCB were confined in the laboratory with nine genotypes from the previously described field area. SCB adults were allowed to feed on healthy, undamaged terminal stolon segments of St. Augustinegrass. Stolon segments, which were replaced weekly, were $\approx 100 \mathrm{~mm}$ long and had two to four nodes. Except for roots on the lowermost node and sheaths on the uppermost node, leaves and roots were removed. The rooted end of each stolon segment was inserted into a water-filled glass tube $(10 \times 75 \mathrm{~mm})$, which was tightly secured with a band of Parafilm (American Can Co., Greenwich, Conn.) wrapping. An experimental unit was a stolon segment in a tube and one male and one female SCB, all enclosed in a glass culture tube $(25 \times 150 \mathrm{~mm})$. Culture tubes were covered with a double layer of Kimwipes (Kimberly-Clark Corp., Roswell, Ga.), fastened to the tube rims with either rubber cement or a band of Parafilm. Number of eggs and adult survival were recorded weekly for 5 weeks. Because eggs were removed weekly, nymphs were absent. There were 20 blocks (replications) of the nine grass genotypes. Laboratory colony SCBs were confined on 10 blocks, and field-collected SCBs were confined on the other 10 blocks. Because there was no grass genotype $\times$ SCB source (colony or field) interaction $(P>0.05)$, SCB source was considered a blocking vari- 
able. Oviposition rate (eggs per female per week) was calculated, with weeks pooled as a repeated measure. For calculating oviposition, females that died were not considered missing. At 5 weeks, adult survival (males + females) also was analyzed. Field and laboratory data were subjected to analysis of variance, and laboratory data were used to predict field data using regression analysis.

In the second experiment, 10 polyploid St. Augustinegrass genotypes were planted on 19 May 1988 at A. Duda \& Sons Sod Farm near LaBelle, Fla. Plots were $3.0 \times 3.0 \mathrm{~m}$, planted from an undivided $0.30 \times 0.46-\mathrm{m}$ tray. There were six blocks (replicates) of each genotype. The field was relatively well-drained and dry and was irrigated by subsurface seepage from lateral ditches. Plots were fully covered by Mar. 1989. SCB adults and nymphs were first noticed on 11 July 1990, but no insecticide was applied. Extent of damage was estimated visually on 29 Oct. 1990 as percentage of dead canopy. Because of their ability to damage 'Floratam', these SCB were designated polyploid damaging population (PDP) (Busey and Center, 1987) SCB.

To estimate resistance in the laboratory, PDP SCB were confined in the laboratory with the 10 genotypes from the field, as part of a previously reported bioassay of 20 genotypes (Busey, 1990b). SCB adults were allowed to feed on stolon segments inserted into waterfilled, glass tubes, as previously described, except there were six blocks (replications) and the experiment continued for 4 weeks. Two SCB colonies were used (PDP-1 from Orange County, Fla., and PDP-2 from Hendry County, Fla.). Colonies had been maintained in the laboratory on 'Floratam' for $\geq 1$ year (Busey, $1990 \mathrm{~b}$ ) and were the same as those used by Busey and Center (1987). Colonies were pooled for means presentation because there was no grass genotype $\times$ SCB colony interaction $(P>$ 0.05 ). Besides oviposition rate, excreta (indicating degree of feeding activity) were rated visually on a 0 to 3 scale, with $0=$ no visible excreta deposit on culture tube; $1=$ a single excreta droplet $<1 \mathrm{~mm}$ in diameter present; 2 = noticeable, several droplets; and $3=$ extremely heavy deposit.

\section{Results and Discussion}

In the first experiment, frequency of damage by the SCB varied among grass genotypes $(P<0.0001)$, with mean frequencies varying from 1.02 occurrences per year for FX-22 and FX-338 to zero for 'Floratam' (Table 1). Extent of damage during two subsequent years with no insecticides differed among grass genotypes $(P<0.0001)$, varying from $86 \%$ damage for FX-313 to 0\% for 'Floratam' (Table 1). For the nine grass genotypes evaluated in the laboratory, oviposition rates of confined chinch bugs varied $(P<0.0001)$ from 22.4 eggs/ female per week on 'Florida Common' to 1.2 eggs/female per week on 'Floratam' (Fig. 1). SCB survival after 5 weeks varied from $85 \%$ on FX-313 to $5 \%$ on 'Floratam' (data not presented). Laboratory oviposition rate predicted $(P<0.0001)$ field damage, frequency,
Table 1. Frequency and extent of damage to 20 St. Augustinegrasses by the southern chinch bug in field plots at Fort Lauderdale Research and Education Center from 1987 to 1991. Means of eight replications.

\begin{tabular}{llcc}
\hline \hline Genotype & Ploidy & $\begin{array}{c}\text { Frequency of damage } \\
\text { (occurrences per year) }\end{array}$ & $\begin{array}{c}\text { Extent of } \\
\text { damage }(\%)^{\mathrm{y}}\end{array}$ \\
\hline FX-22 & Diploid & 1.02 & 62 \\
FX-29 & Diploid & 0.90 & 84 \\
FX-338 & Diploid & 1.02 & 76 \\
Florida Common & Diploid & 0.90 & 81 \\
FX-74 & Diploid & 0.68 & 63 \\
FX-28 & Diploid & 0.78 & 73 \\
FX-234 & Diploid & 0.66 & 69 \\
FX-332 & Diploid & 0.48 & 56 \\
FX-281 & Diploid & 0.54 & 54 \\
FX-51 & Diploid & 0.36 & 52 \\
Bitterblue & Polyploid & 0.24 & 53 \\
FX-148 & Diploid & 0.18 & 68 \\
FX-261 & Diploid & 0.12 & 54 \\
FX-313 & Diploid & 0.18 & 86 \\
Seville & Diploid & 0.18 & 45 \\
FX-299 & Diploid & 0.18 & 72 \\
FX-305 & Diploid & 0.12 & 34 \\
FX-36 & Diploid & 0.06 & 59 \\
FX-41 & Polyploid & 0.06 & 25 \\
Floratam & Polyploid & 0.00 & 0 \\
Statistics & & & $10.22^{* * * *}$ \\
F-test & & & 32 \\
CV & & $5.82^{* * * *}$ & 17 \\
MSD & & 85.00 & \\
\hline
\end{tabular}

${ }^{2}$ Recurrent damage during 2.08 years of remedial insecticide application.

${ }^{y}$ Portion of canopy dead from progressive damage subject to no insecticides, average of 5 months over 2 years.

${ }^{\times} \mathrm{CV}=$ coefficient of variation; MSD = minimum significant differences; these differences were by the Waller-Duncan Bayesian k ratio $t$ test at $\mathrm{k}=100$ and $P \leq 0.05$.

${ }^{* * *}$ Significant at $P \leq 0.001$.

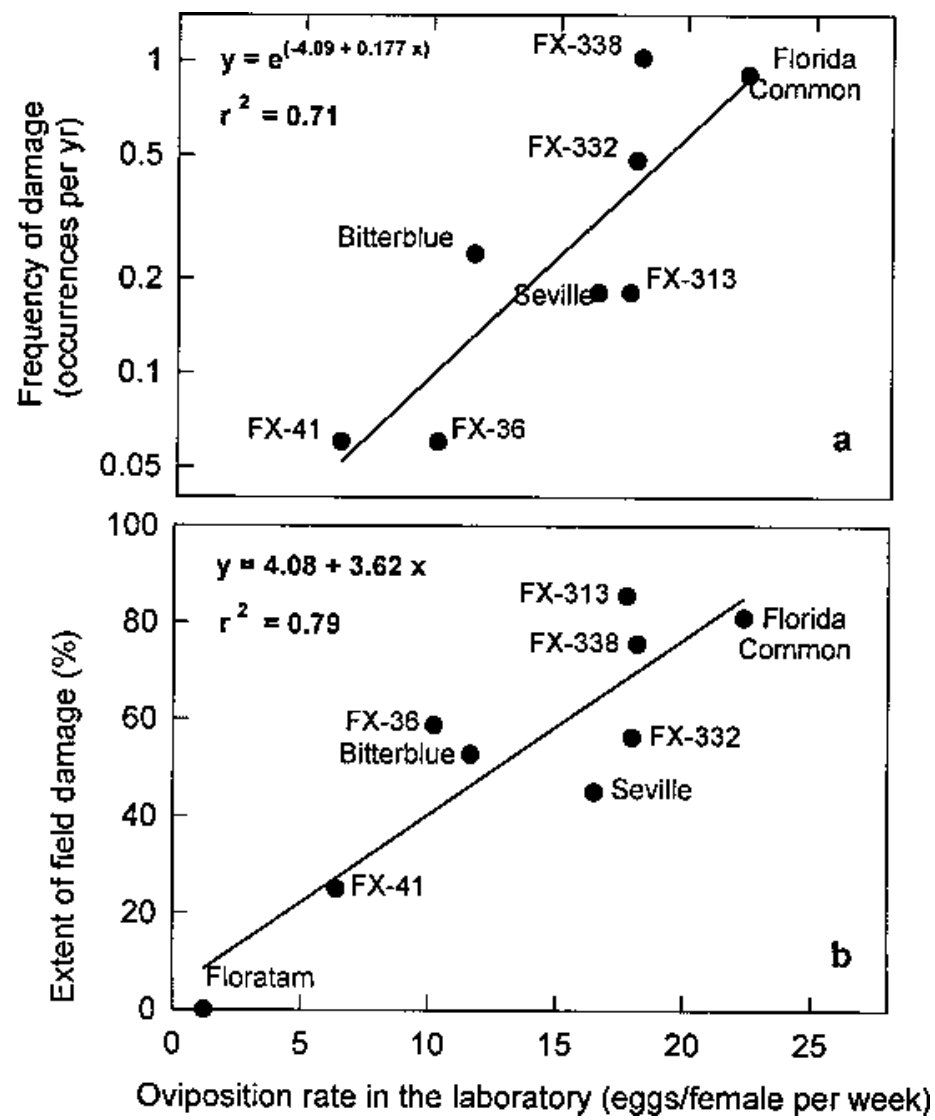

Fig. 1. Field damage by the southern chinch bug (SCB) to nine St. Augustinegrass genotypes (y axes) at Fort Lauderdale Research and Education Center as a function of oviposition rate in the laboratory ( $\mathrm{x}$ axis). Means of eight and 20 replications for field and laboratory, respectively. (a) Frequency of recurring SCB field damage (log-scale) over 2.08 years with remedial insecticide application. ('Floratam' had zero damage; thus, it could not be plotted on a log scale.) (b) Extent of progressive SCB field damage, average over 2 years of 5 monthly observations with no insecticides. 
and extent $\left(r^{2}=0.71\right.$ and 0.79 , respectively; Fig. 1). SCB laboratory survival (data not presented) predicted $(P<0.0001)$ extent of damage $\left(r^{2}=0.84\right)$ but not frequency.

In the second experiment, extent of damage differed $(P<0.0001)$ among polyploid $\mathrm{St}$. Augustinegrasses (Fig. 2a). Extent of damage varied from $90 \%$ for 'Bitterblue' to $0 \%$ for 'FX-10'. Oviposition rate differed among genotypes (Busey, 1990b) and predicted $(P<0.01$; $\left.r^{2}=0.67\right)$ extent of damage. Excreta rating predicted $\left(P<0.05 ; r^{2}=0.57\right)$ extent of damage (Fig. 2b)
Laboratory and field studies provide different drawbacks for evaluating resistance to SCB. Chinch bug damage required 14 and 29 months to occur in the field. That time may be needed to develop sufficient thatch, which is associated with abundance of hairy chinch bug (Blissus leucopterus hirtus Montandon) (Davis and Smitley, 1990a, 1990b). Field studies of the SCB are complicated by environment (e.g., fertilization practice) and the progressive nature of outbreak, resulting in asynchronous damage among replications (Busey and Snyder, 1993). Laboratory bioassays are

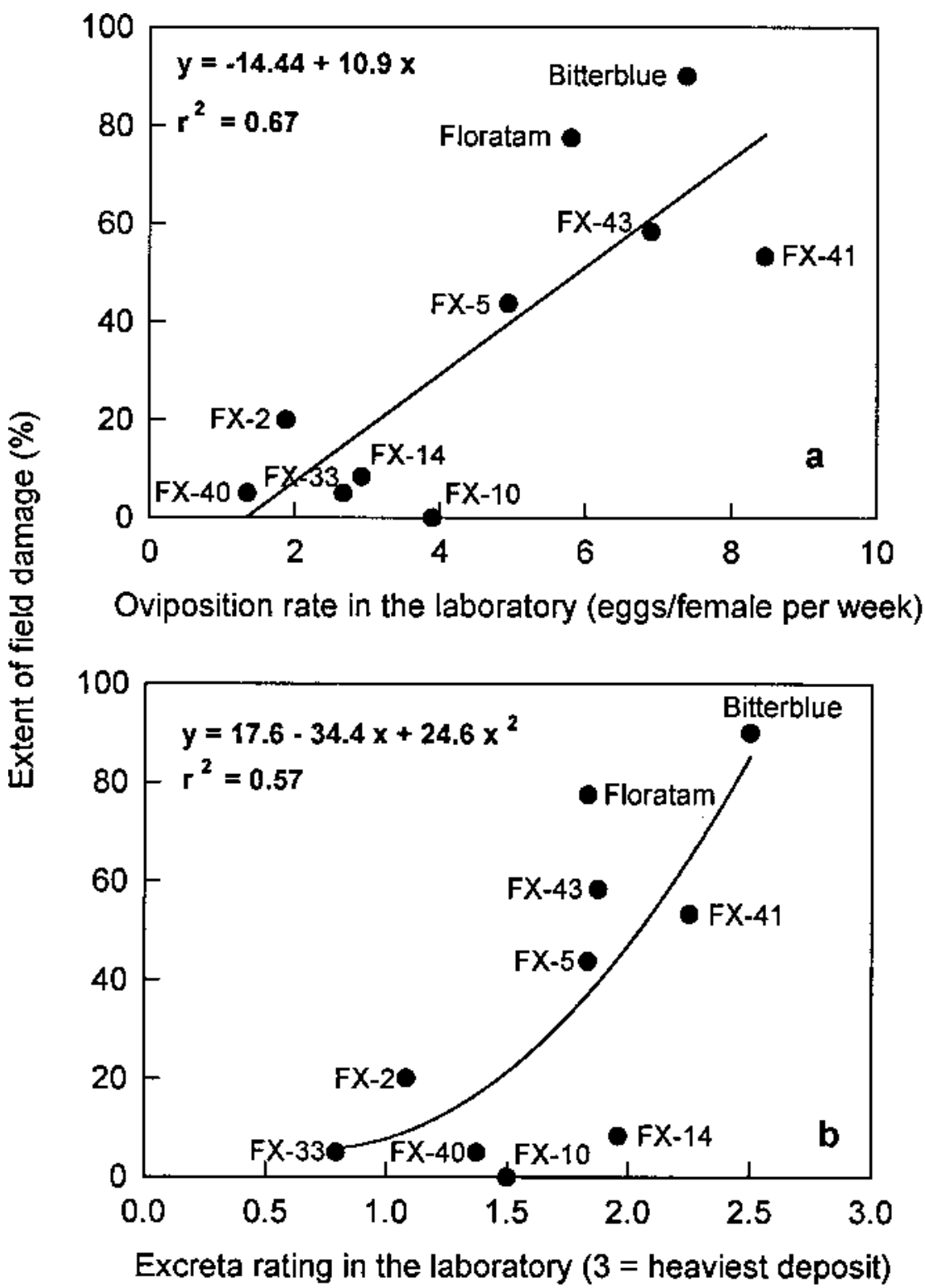

Fig. 2. Extent of southern chinch bug (SCB) field damage to 10 polyploid St. Augustinegrasses (y axis) at a sod farm near LaBelle, Fla., as a function of host suitability in the laboratory (x axes). Means of six replications for field and laboratory. (a) Field damage and SCB oviposition rate; (b) field damage and SCB excreta rating. sensitive to age of SCB (Busey, 1990a), acclimation (Busey, 1990b), and crowding (P.B., unpublished). Field and laboratory studies are affected by genetic adaptation of SCB populations (Busey, 1990a; Busey and Center, 1987). In this study, genotypes resistant in the field, such as 'Floratam' and 'FX-10', with <20\% canopy damage by the STD and PDP SCBs, respectively, supported $<5$ eggs/female per week in the laboratory. This result is consistent with the reported threshold for SCB resistance, an oviposition rate of $<5$ eggs/female per week (Busey, 1990a, 1990b). The parallelism of field and laboratory data is encouraging because it shows that laboratory bioassays are a valid predictor of field resistance. To my knowledge, this study is the first to report field resistance to the SCB among St. Augustinegrasses.

\section{Literature Cited}

Busey, P. 1986. Morphological identification of St. Augustinegrass cultivars. Crop Sci. 26:28-32.

Busey, P. 1990a. Inheritance of host adaptation in the southern chinch bug (Heteroptera: Lygaeidae). Ann. Entomol. Soc. Amer. 83:563567.

Busey, P. 1990b. Polyploid Stenotaphrum germplasm: Resistance to the polyploid damaging population southern chinch bug. Crop Sci. 30:588-593

Busey, P. 1993. Registration of FX-10 St. Augustinegrass. Crop Sci. 33:214-215.

Busey, P. and B.J. Center. 1987. Southern chinch bug (Hemiptera: Heteroptera: Lygaeidae) overcomes resistance in St. Augustinegrass. J. Econ. Entomol. 80:608-611.

Busey, P., R.M. Giblin-Davis, C.W. Riger, and E.I. Zaenker. 1991. Susceptibility of diploid St. Augustinegrasses to Belonolaimus longicaudatus. J. Nematol. Suppl. 23(4S):604 610.

Busey, P and G.H. Snyder. 1993. Population outbreak of the southern chinch bug is regulated by fertilization. Intl. Turfgrass Soc. J. 7:353-357.

Busey, P. and E.I. Zaenker. 1992. Resistance bioassay from southern chinch bug (Heteroptera: Lygaeidae) excreta. J. Econ. Entomol. 85:20322038.

Davis, M.G.K. and D.R. Smitley. 1990a. Association of thatch with populations of hairy chinch bug (Hemiptera: Lygaeidae) in turf. J. Econ. Entomol. 83:2370-2374.

Davis, M.G.K. and D.R. Smitley. 1990b. Relationship of hairy chinch bug (Hemiptera: Lygaeidae) presence and abundance to parameters of the turf environment. J. Econ. Entomol. 83:23752379.

Horn, G.C., A.E. Dudeck, and R.W. Toler. 1973 'Floratam' St. Augustinegrass: A fast growing new variety for ornamental turf resistant to St. Augustine decline and chinch bugs. Florida Agr. Expt. Sta. Circ. S-224, Gainesville.

Quisenberry, S.S. 1990. Plant resistance to insects and mites in forage and turf grasses. Fla. Entomol. 73:411-421

Reinert, J.A. and A.E. Dudeck. 1974. Southern chinch bug resistance in St. Augustine-grass [sic]. J. Econ. Entomol. 67:275-277. 